\title{
Cross-sectional survey on home mechanical ventilator use: major deficiencies in a home care system in South Korea
}

\author{
Kyunghyun Song ${ }^{1}$, Sei-Won Kim², Yun Su Sim ${ }^{3}$, Tai Sun Park ${ }^{4}$, Young Seok Lee ${ }^{5}$ Jick Hwan Ha ${ }^{6}$, \\ Ji Young Park ${ }^{1}$, Ki-Suck Jung ${ }^{1}$, Sunghoon Park ${ }^{1}$ \\ ${ }^{1}$ Department of Pulmonary, Allergy and Critical Care Medicine, Hallym University Sacred Heart Hospital, Anyang, Korea; ${ }^{2}$ Division of Pulmonary, \\ Critical Care and Sleep Medicine, Eunpyeong St. Mary's Hospital, The Catholic University of Korea, Seoul, Korea; ${ }^{3}$ Division of Pulmonary, Allergy \\ and Critical Care Medicine, Hallym University Kangnam Sacred Heart Hospital, Seoul, Korea; ${ }^{4}$ Department of Internal Medicine, Hanyang \\ University Guri Hospital, Guri, Korea; ${ }^{5}$ Division of Pulmonary, Allergy, and Critical Care Medicine, Department of Internal Medicine, Korea \\ University Guro Hospital, Seoul, Korea; ${ }^{6}$ Department of Pulmonary and Critical Care Medicine, Incheon St. Mary's Hospital, College of Medicine, \\ The Catholic University of Korea, Inchoen, Korea \\ Contributions: (I) Conception and design: K Song, SW Kim, YS Sim, S Park; (II) Administrative support: TS Park, YS Lee, JY Park, KS Jung; (III) Provision \\ of study materials or patients: SW Kim, YS Sim, S Park; (IV) Collection and assembly of data: K Song, SW Kim, JH Ha, S Park; (V) Data analysis and \\ interpretation: K Song, YS Lee, JH Ha, JY Park, S Park; (VI) Manuscript writing: All authors; (VII) Final approval of manuscript: All authors. \\ Correspondence to: Sunghoon Park. Department of Pulmonary, Allergy and Critical Care Medicine, Hallym University Sacred Heart Hospital, \\ 22 Gwanpyeong-ro, Anyang 14068, Korea. Email: f2000tj@gmail.com.
}

Background: Despite the increased use of home mechanical ventilation (HMV), data on home care services for HMV users in Asian countries are scarce. This study investigated the current status of HMV use in the Seoul metropolitan area.

Methods: This cross-sectional study involved three university-affiliated hospitals. Subjects who were receiving HMV at home for $>3$ months were included, and door-to-door visits were done to collect data (e.g., on devices, caregivers, and healthcare service use) from the subjects or their families.

Results: Among the 140 individuals who were initially screened, 38 adults and 26 children were finally enrolled; the duration of HMV use was 14.5 (8.8-37.5) months and 20.5 (7.0-28.0) months, respectively. Tracheostomy ventilation was performed in $36.8 \%$ of the adults and $61.5 \%$ of the children, and life-support ventilator in $55.3 \%$ and $96.2 \%$, respectively. Regarding ancillary devices, $42.1 \%$ of the adults and $80.8 \%$ of the children had an oxygen monitoring device, while only one member of each group had a cough assist device. Among those with a tracheostomy, $64.3 \%$ of adults and $81.3 \%$ of children had an AMBU-bag. Reliance on a family member for care was determined in $65.8 \%$ of adults and $88.5 \%$ of children, but a home visit by a hospital nurse during the previous year occurred in only $26.3 \%$ of the adults and $3.8 \%$ of the children. Emergency incidents at home occurred in $39.5 \%$ of the adults and $50.0 \%$ of the children, with dyspnea being the most common cause. Out-of-pocket expenses tended to be higher in the tracheostomy ( $v s$. non-tracheostomy) group and in children ( $v s$. adults).

Conclusions: Our study highlights the challenges faced by adults and children dependent on HMV, and their families. There is an urgent need for nationwide standardization of care for patients receiving HMV at home.

Keywords: Home; ventilation; safety; tracheostomy

Submitted Feb 10, 2021. Accepted for publication Jun 09, 2021.

doi: $10.21037 /$ jtd-21-269

View this article at: https://dx.doi.org/10.21037/jtd-21-269

(C) Journal of Thoracic Disease. All rights reserved. 


\section{Introduction}

Since the introduction of noninvasive ventilation, the use of home mechanical ventilation (HMV) has steadily increased worldwide (1-5). This is also the case in South Korea, where the use of HMV has rapidly increased since 2016, when the Korean National Health Insurance Service (NHIS) started to reimburse the costs of HMV (6-8).

The estimated rate of HMV use in a European survey was 6.6 per 100,000 people, with the highest rate reported in France (17/100,000 people) (1). In South Korea, the NHIS has estimated a prevalence of 9.3 per 100,000 people, where hospitalized patients for long-term care were included (8). However, both the prevalence and quality of HMV-based care are likely to differ among countries (9-14).

Previously, transition of mechanically ventilated patients from the hospital to family-centered home care was associated with greater cost-effectiveness, decreased risk of infection, and an improved quality of life $(9,10)$. However, family members frequently face emotional, physical, and financial burdens associated with the use of HMV, and safety incidents are a major concern, particularly for patients with a 24-h ventilation requirement (11-13). For these reasons, regional home care organizations with help-lines have been implemented in several Western countries $(14,15)$.

In home care support systems, assessment of patient safety and quality of life is important. However, relevant data are still lacking in Asian countries. Therefore, the aim of this cross-sectional survey was to characterize the present status of HMV use (e.g., ventilator machines, ancillary devices, caregivers, safety incidents, healthcare service use, etc.) in South Korea. This information will be valuable for assessing the needs of HMV users and their families, and could further improve home care systems.

We present the following article in accordance with the STROBE reporting checklist (available at https://dx.doi. org/10.21037/jtd-21-269).

\section{Methods}

\section{Study population}

This study was performed during June to August 2020 in three university-affiliated hospitals located in the Seoul metropolitan area (South Korea). All patients who had initiated HMV in the three hospitals were screened, but only those who were discharged and had been using HMV at home for $>3$ months were included. Patients using an HMV machine in the hospital or nursing home, and those with obstructive sleep apnea (OSA), were excluded. After confirmation by telephone, door-to-door visits of all eligible patients were conducted. Home care systems were investigated based on face-to-face interviews with the patients or their families. Ventilator parameters were obtained directly from the patient's ventilator, and the patients' clinical information, including primary diagnosis for HMV, was extracted from the medical records. This study was approved by Hallym University Institutional Review Board (No. 2020-02-018), as well as by two other institutes, and was conducted according to the Declaration of Helsinki. Written consent was obtained from all the participating subjects or their legal guardians.

\section{Data collection}

Data were obtained on the following: demographic characteristics (age, sex, type of housing facility, and family members); comorbidities; feeding methods; interfaces (tracheostomy, facial masks or nasal masks); HMV duration; caregivers; home visit services for ventilator check-ups by a HMV equipment provider and home care services delivered by a hospital (registered) nurse; the occurrence of emergencies (safety incidents), defined as emergency calls to a helpline or emergency department visits; and healthcare service use (i.e., visiting an outpatient office or emergency department, or hospitalization) (Supplementary file).

The type of ventilator machine, mask, circuit, and ventilator modes, as well as the time (hours/day) of HMV use, were investigated. The use of ancillary devices, such as oxygen and carbon dioxide $\left(\mathrm{CO}_{2}\right)$ monitors, cough-assist (inexsufflator), chest wall oscillation, artificial manual breathing unit (AMBU)-bags, and oxygen generators, was also investigated. In patients with a tracheostomy, suction devices were documented. In this study, life support ventilators were defined as ventilators with both volume and pressure modes as well as advanced monitoring systems, and considered appropriate for highly ventilator-dependent patients $(6,8)$. Mortality among the enrolled patients during the follow-up period (8 months) was also determined.

South Korea has a single-payer system (the NHIS), which consists of two major healthcare programs for universal coverage of all residents; National Health Insurance (approximately 97.0\%) and Medical Aid (3.0\%) (16). In a previous report using NHIS data, the estimated monthly cost of HMV use (i.e., of devices, interfaces, and circuits) in South Korea was $\$ 569.20$ per person; $90 \%$ of the 


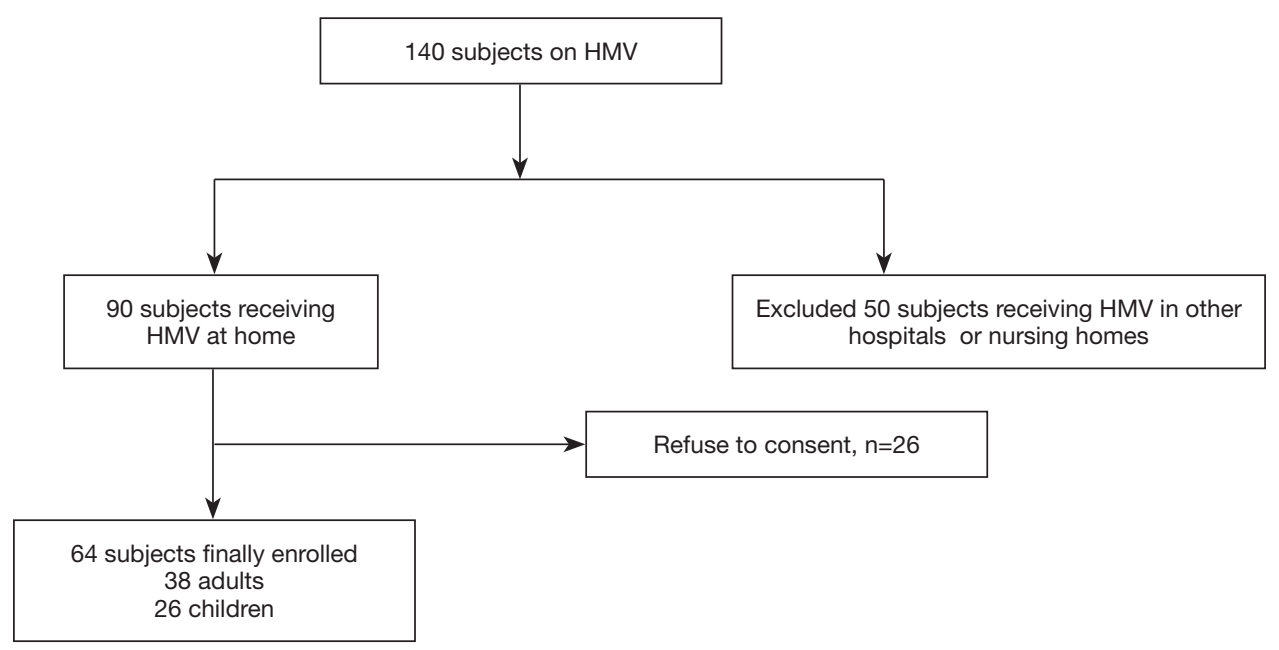

Figure 1 Flowchart of enrolled patients. HMV, home mechanical ventilation.

cost was reimbursed by the government (8). In the present study, we investigated the type of insurance of the enrolled subjects and their out-of-pocket expenses associated with HMV use.

\section{Data analyses}

We divided the enrolled patients into adults ( $>18$ years) and children ( $\leq 18$ years). All results are presented as numbers with percentages for categorical variables, and as medians with interquartile ranges (IQR) for continuous variables. The Mann-Whitney $\mathrm{U}$ test was used to compare continuous variables, and the chi-squared or Fisher's exact test was employed to compare categorical variables. However, mostly, descriptive analyses were used to describe the characteristics of subjects receiving HMV at home. And, missing data were not imputed. All probability values were two-sided and a $\mathrm{P}$ value $<0.05$ was considered statistically significant. IBM SPSS version 25.0 software for Windows (IBM Corp., Armonk, NY, USA) was used for all statistical analyses.

\section{Results}

\section{Subject characteristics}

Of 140 patients with HMV, 90 receiving HMV at home were initially enrolled. However, after the exclusion of those who did not provide consent, 64 patients (38 adults and 26 children) were finally included in this study (Figure 1).

The median age of the adults was 67.0 years $(56.0-$
77.0 years) and $55.3 \%$ were female; the median duration of HMV use was 14.5 months (8.8-37.0 months). Regarding the primary indications for HMV use, chronic obstructive pulmonary disease [COPD, $n=14(36.8 \%)$ ] was the most common, followed by unspecified respiratory disorders $(\mathrm{n}=7)$, kyphoscoliosis $(\mathrm{n}=3)$, and amyotrophic lateral sclerosis (ALS, n=3) (Table 1 and Table S1). Among the adults, the most common underlying comorbidities were COPD and hypertension. The median age of the children included in the study was 6.5 years (4.0-13.2 years); nine of the children were female. The median duration of HMV use was 20.5 months (7.0-28.0 months), and the most common primary diagnosis for $\mathrm{HMV}$ use was unspecified respiratory disorder $(n=7)$, followed by congenital respiratory disorder $(\mathrm{n}=5)$ and myopathy $(\mathrm{n}=5)$.

\section{Ventilator machines, interfaces, and ancillary devices}

Life-support ventilators were used in $55.3 \%$ of adults, and spontaneous/timed (S/T) mode was the most commonly used ventilator mode (Table 2). Tracheostomy ventilation was performed in $36.8 \%$ of adults, and single-limb circuit with a leak valve was the most commonly used circuit configuration (97.4\%). Regarding ancillary devices (Table 3), $42.1 \%$ of adults had an oxygen saturation monitoring device at home. Although all 14 patients with a tracheostomy had a suction device, 5 patients (35.9\%) had not been equipped with an AMBU-bag.

Among the children, 96.2\% used a life-support ventilator and S/T was the most commonly used mode. Tracheostomy 
Table 1 Demographics of enrolled patients

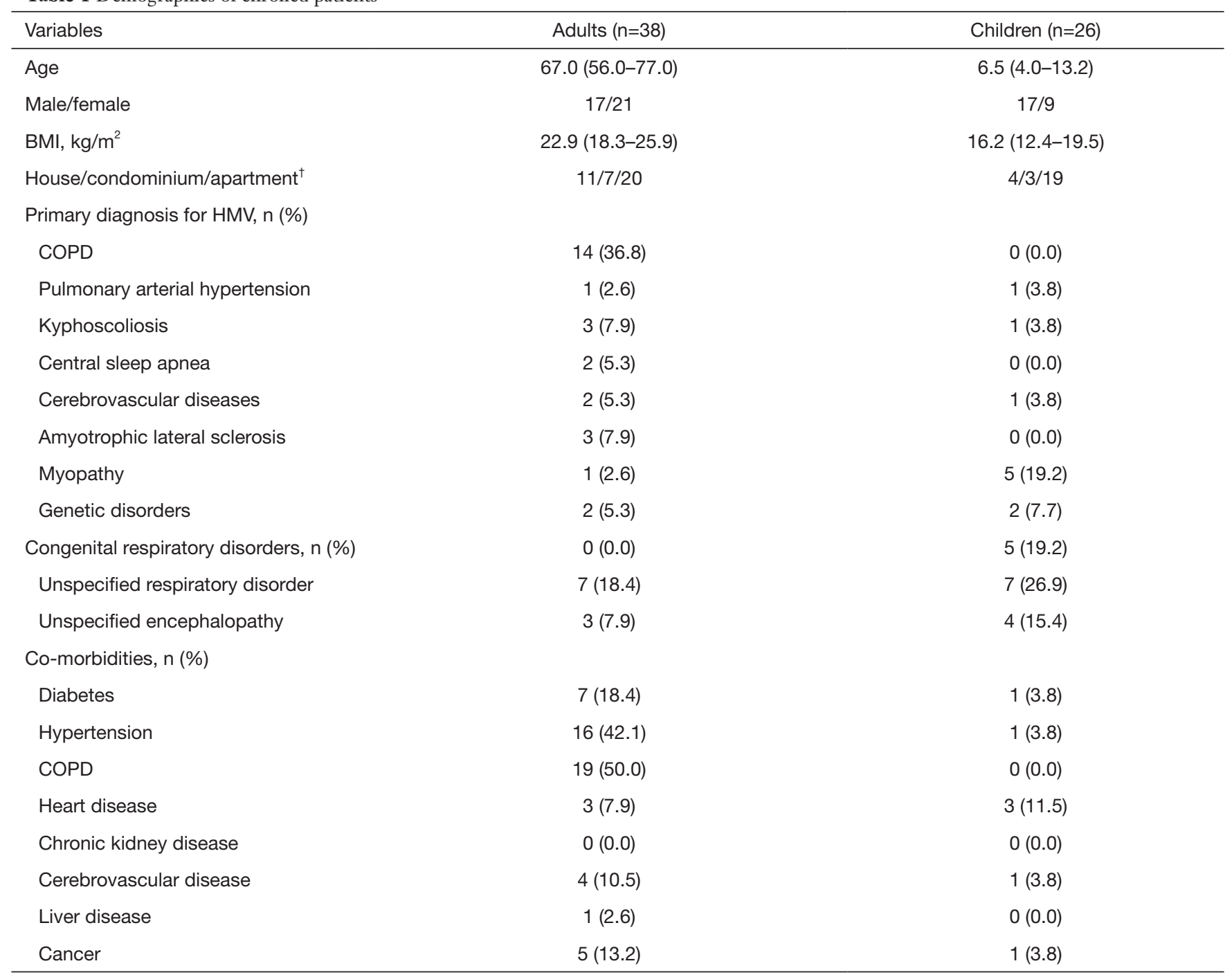

${ }^{\dagger}$, housing types. BMI, body mass index; COPD, chronic obstructive pulmonary disease; HMV, home mechanical ventilation.

ventilation was performed in $61.5 \%$ of children; a nasal mask was used by $30.8 \%$ of this group. In the survey of ancillary devices, $80.8 \%$ of the children had an oxygen saturation monitoring device at home. Among those with a tracheostomy, $3(18.7 \%)$ had not been equipped with an AMBU-bag.

\section{Safety incidents and medical care service}

For $65.8 \%$ of the adults care was provided by family members, and for $18.2 \%$ by a privately hired caregiver (Table 4). All but one of the adults was regularly visited (i.e., ventilator check-ups) by an equipment provider (12 visits/ year) but only $26.3 \%$ of them had been visited by a hospital nurse during the previous year. Emergencies (or safety incidents) at home during the previous year were reported by $39.5 \%$ of the adults, with dyspnea being the most common cause (Table S2), and $13.2 \%$ of the adults visited emergency departments.

Among the pediatric group, $88.5 \%$ were being cared for by family members, and $11.5 \%$ by a privately hired caregiver. All but one of the children had regular visits by an equipment provider but only one had been visited by a hospital nurse during the previous year. Half of the children experienced an emergency at home, and $34.6 \%$ had visited emergency departments during the previous year.

During the 8-month follow-up, 7 (18.4\%) adults and 2 
Table 2 Parameters associated with home mechanical ventilation

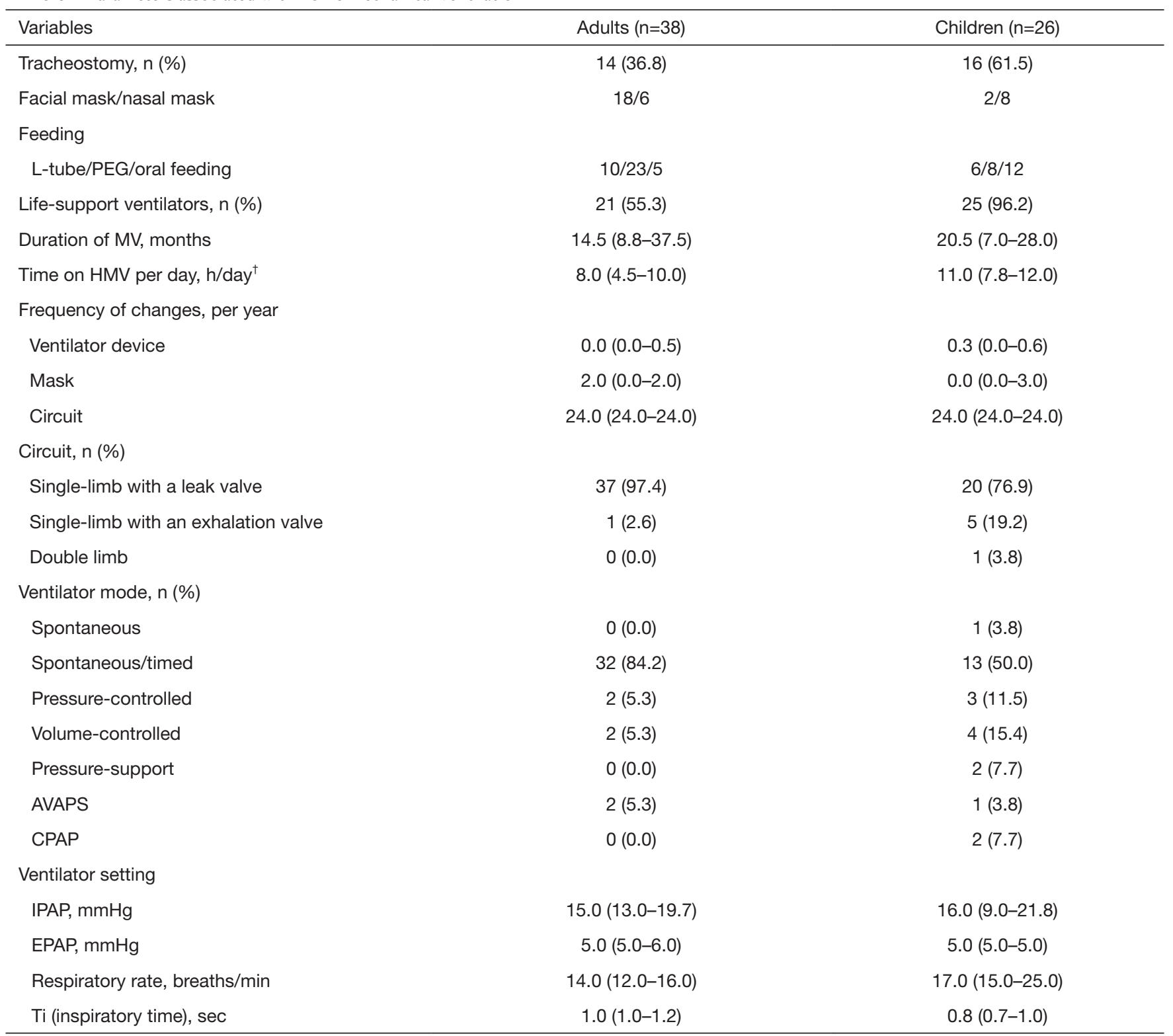

${ }^{\dagger}$, among 34 patients who received HMV via a mask. AVAPS, averaged volume-assured pressure support; CPAP, continuous positive airway pressure; EPAP, expiratory positive airway pressure; HMV. Home mechanical ventilation; IPAP, inspiratory positive airway pressure; MV, mechanical ventilation; PEG, percutaneous endoscopic gastrostomy.

(7.7\%) children died. Details are presented in Table S3.

\section{Subjects with tracheostomy ventilation}

Thirty (46.9\%) patients had a tracheostomy, and more than two-thirds of whom were cared for by family members (Table 5). During the total period of HMV use, patients with tracheostomy ventilation tended to be hospitalized more frequently and had more out-of-pocket expenses than patients receiving HMV via a mask.

\section{Discussion}

Despite the increasing prevalence of HMV use worldwide $(2,8,17)$, very few data on HMV use in Asian countries are available. In South Korea, the reported prevalence was 
Table 3 Ancillary devices

\begin{tabular}{lcc}
\hline Devices & Adults $(\mathrm{n}=38), \mathrm{n}(\%)$ & Children $(\mathrm{n}=26), \mathrm{n}(\%)$ \\
\hline Oxygen saturation monitoring device & $16(42.1)$ & $21(80.8)$ \\
$\mathrm{CO}_{2}$ monitoring device & $0(0.0)$ & $0(0.0)$ \\
Cough assist (in-exsufflator) & $1(2.6)$ & $1(3.8)$ \\
Chest wall oscillation $_{\text {Suction device }}^{\dagger}$ & $2(5.3)$ & $0(0.0)$ \\
AMBU-bag $^{\dagger}$ & $14(100.0)$ & $16(100.0)$ \\
Oxygen generator & $9(64.3)$ & $13(81.3)$ \\
\hline
\end{tabular}

${ }^{\dagger}$, among 30 patients with tracheostomy; 14 adults and 16 children. AMBU, artificial manual breathing unit.

Table 4 Use of medical care service

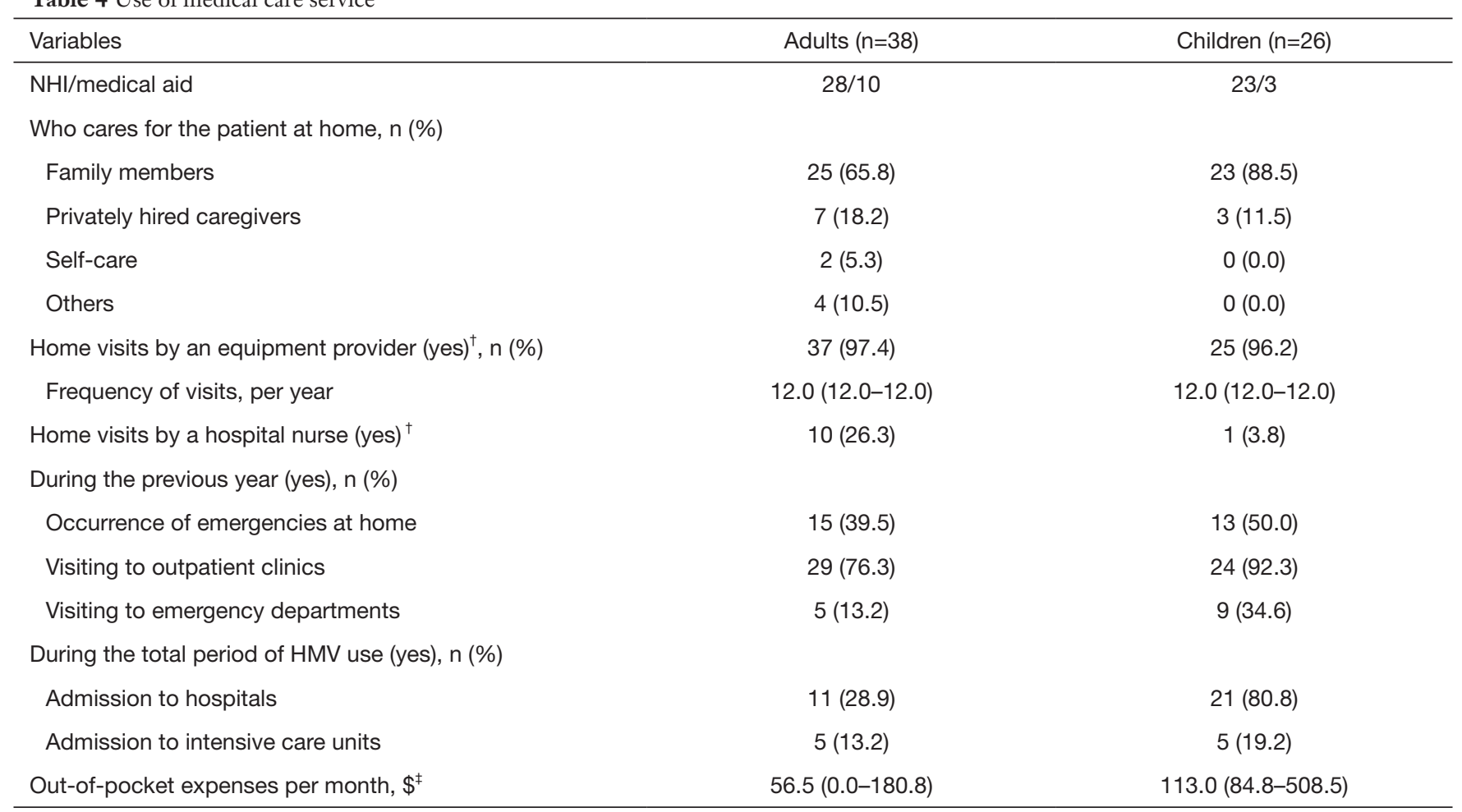

${ }^{\dagger}$, any visits during the previous 1 year [number of patients (percentage)]; ${ }^{\ddagger}$, adult, $n=35$; children/adolescents, $n=25 ; 1 \$=1,130$ Korean won. HMV, home mechanical ventilation; $\mathrm{NHI}$, national health insurance.

relatively high (8), but standard of care is not well defined and no national guidelines exist for HMV users. For these reasons, we aimed to evaluate current practices and potential deficiencies in care provision. Although our study was limited to several parts of the Seoul metropolitan area, the findings in other areas of South Korea are likely to be similar, because most of the patients in our cohort lived in urban areas where the healthcare system and infrastructure are relatively well established.

Our cross-sectional study yielded several important findings. First, the majority of the patients were cared for by family members; aside from regular visits by equipment providers, home care services delivered by a hospital nurse were rare. Second, while one-third of the included adults 
Table 5 Use of medical care service between patients with tracheostomy versus those without

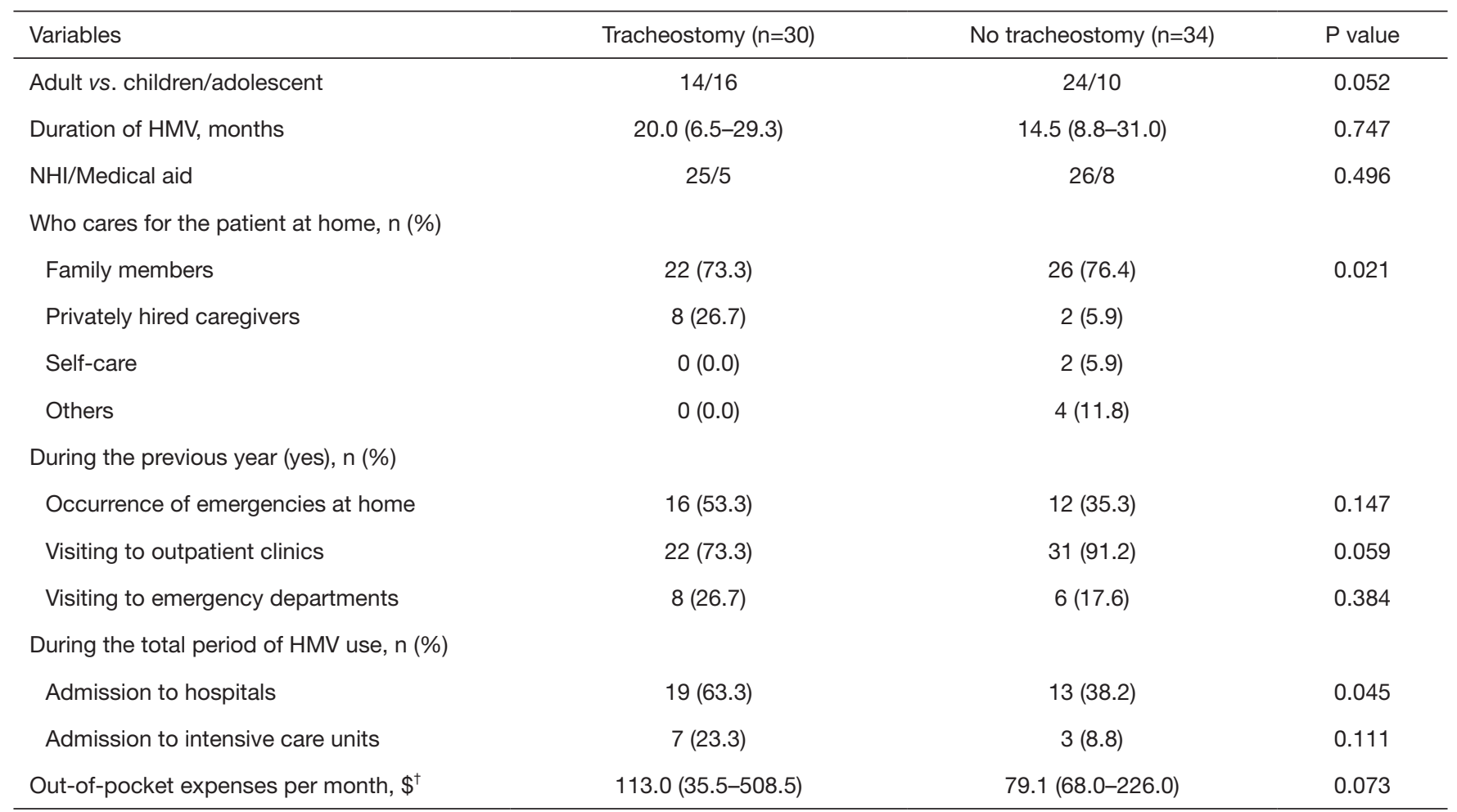

${ }^{\dagger}$, number of subjects $=60 ; 1 \$=1,130$ Korean won. HMV, home mechanical ventilation; $\mathrm{NHI}$, national health insurance.

and more than one half of the children received HMV via tracheostomy, many had not been equipped with the ancillary devices, such as an oxygen monitoring device or AMBU-bag, which are necessary in emergency situations. Finally, a substantial number of patients still had emergency incidents at home or required re-hospitalizations.

The most common primary diagnosis for HMV use in our adult patients was COPD, in contrast to previous studies of Korean populations in which neuromuscular disorder was the most common diagnosis $(8,18)$. Although the difference may be partly due to the small sample size of our study, there may also be regional differences in the prevalence of particular primary diagnoses, as shown in a study of HMV users in Australia and New Zealand (10). In addition, the proportion of patients requiring tracheostomy ventilation $(36.8 \%)$ was higher in our study than in European countries (13.0\%) and Hong Kong $(5.2 \%)(1,19)$. Together with the prevalence of tracheostomy, the high proportion of adults who used a life support ventilator or who were fed by a feeding tube reflected the high dependency (or low level of autonomy) of our study population.

The most common primary diagnosis in our pediatric patients slightly differed from that reported in comparable studies from other countries $(20,21)$. Nonetheless, our results are quite similar to those reported by Park et al. (7), who found a high prevalence of tracheostomy ventilation and that only $20 \%$ of children received home nursing care by a hospital nurse. Another notable finding of our study was that many children required hospitalization or intensive care unit (ICU) admission during the period of HMV use. These results highlight the substantial demands for healthcare services among children receiving HMV at home.

Although patients with OSA were excluded from our study, continuous positive airway pressure (CPAP) mode was applied in two children (one with bronchopulmonary dysplasia and one with congenital malformations of the trachea and bronchus). However, the reasons were unclear. Except for that, neither the ventilator mode nor circuit configuration of the HMVs were remarkable (Table 2). Although the total duration of HMV use after HMV initiation was shorter in our cohort ( $<3$ years) than in other countries $(10,19)$, the daily amount of time on HMV, as an indicator of HMV adherence, among patients ventilated via a mask was comparable. However, due to the small 
sample size, risk factors affecting adherence could not be investigated and await further large-scale studies.

Seven ancillary devices were investigated in our survey, but not all patients on HMV needed them. The Canadian Thoracic Society (22) and German National Guideline Commission (23) defined the indications for various ancillary devices. A cough-assist device is recommended for patients with tracheostomy, and for at-risk individuals (i.e., a peak cough flow $<270 \mathrm{~L} / \mathrm{min}$ ). A suction device and AMBU-bag are usually indicated for invasive ventilation, and pulse oximetry for patients with invasive ventilation or a specific disease category. However, in our cohort, a substantial number of adults and children had not been equipped with an oxygen monitoring device or AMBU-bag at home, leaving them vulnerable to emergency situations at home.

Although emergency incidents were defined arbitrarily in our study, more than one-third of the patients reported an incident at home, with various causes. While many technical issues associated with ventilator machines can be resolved by experienced equipment providers, a patient may deteriorate clinically for reasons other than ventilator malfunction (13). Accordingly, regular home visits service by a hospital (or specialized) nurse are crucial to resolve or prevent serious problems. The most recent German national guidelines (23) recommend regular check-ups for HMV users, with the interval depending on the underlying diseases, the patient's stability, and the care setting. A multidisciplinary and multisector collaboration was also emphasized, along with strict qualifications for nurses and equipment providers. Hence, considering the high prevalence of HMV use in South Korea (8), countrywide standardization of care for patients receiving HMV at home should be implemented.

Unfortunately, the comparison of mortality rates between patients receiving HMV at home versus in the hospital was not feasible in our study. The three hospitals participating in this study are university-affiliated and HMV patients are rarely admitted to these hospitals for longterm care. In particular, consent from patients who had been transferred to other institutions (e.g., nursing hospitals or nursing homes) would have been difficult to obtain. In addition, in our cohort, the different durations of HMV use and small sample size hindered the comparison of the mortality rates between disease-specific groups. However, neither the baseline characteristics nor ventilator variables differed significantly between adults who survived and those who died (data not shown).
In a prospective study, Nonoyama et al. demonstrated that the cost of healthcare utilization was higher for invasively ventilated (or tracheostomy) patients than for those with noninvasive ventilation; amyotrophic lateral sclerosis and high dependency were significantly associated with high costs in that study (12). Although we could not determine the direct costs associated with hospital (or emergency department) visits, hospitalizations, or caregivers in our study, out-of-pocket expenses tended to be higher in patients with a high degree of dependency (i.e., those with tracheostomy ventilation and children), consistent with the previous study (12). However, the costs attributable to family caregiver time are also important and in previous studies accounted for $18-53 \%$ of the total costs $(24,25)$. Hence, the psychological and physical burdens of the family members of HMV users should be assessed in future investigations (26).

This study had several limitations. The small sample size and its restriction to several parts of the Seoul metropolitan area may have resulted in selection bias and limited the generalizability (and reliability) of our findings. Moreover, the majority of HMV patients in South Korea are likely to be in hospitals (community or nursing) or nursing homes, but these patients were excluded from our study. Furthermore, because our investigation was conducted during the coronavirus disease-19 (COVID-19) pandemic, many patients and caregivers refused door-to-door interviews. Also, we could not investigate type of home care services offered by equipment providers and hospital nurses, and detailed data on medical and non-medical expenses. Furthermore, data on emergency incidents relied on the recall of the patients or their caregivers. More accurate data can be obtained from the on-call log data of HMV companies (27). Finally, HMV might have been initiated after weaning failure, not electively, in some cases. However, despite these limitations, this is the first study to assess actual HMV use in South Korea. Our work is therefore expected to provide important information for future policymaking aimed at improving support systems for home HMV patients.

In conclusion, our study highlights the challenges faced by adults and children dependent on HMV, and their families. Hence, standardization of care and establishment of guidelines for patients receiving HMV at home are urgently needed. Furthermore, large-scale studies will be needed to gain further insight into these challenges and their possible solutions. 


\section{Acknowledgments}

We thank Dr. Seong-Sik Cho (Dong-A University Hospital) for his dedication to the statistical analyses in the study.

Funding: None.

\section{Footnote}

Reporting Checklist: The authors have completed the STROBE reporting checklist. Available at https://dx.doi. org/10.21037/jtd-21-269

Data Sharing Statement: Available at https://dx.doi. org/10.21037/jtd-21-269

Peer Review File: Available at https://dx.doi.org/10.21037/ jtd-21-269

Conflicts of Interest: All authors have completed the ICMJE uniform disclosure form (available at https://dx.doi. org/10.21037/jtd-21-269). WITHMED cooperation supported for Sunghoon Park, Sei-Won Kim and Yun Su Sim's meeting and patient contact. Sunghoon Park received honoraria for a lecture from WITHMED cooperation. WITHMED cooperation helped us for this study, but they were not involved in data analysis and writing the manuscript. The other authors have no conflicts of interest to declare.

Ethical Statement: The authors are accountable for all aspects of the work in ensuring that questions related to the accuracy or integrity of any part of the work are appropriately investigated and resolved. This study was approved by Hallym University Institutional Review Board (No. 2020-02-018), as well as by two other institutes, and was conducted according to the Declaration of Helsinki. Written consent was obtained from all the participating subjects or their legal guardians.

Open Access Statement: This is an Open Access article distributed in accordance with the Creative Commons Attribution-NonCommercial-NoDerivs 4.0 International License (CC BY-NC-ND 4.0), which permits the noncommercial replication and distribution of the article with the strict proviso that no changes or edits are made and the original work is properly cited (including links to both the formal publication through the relevant DOI and the license). See: https://creativecommons.org/licenses/by-nc-nd/4.0/.

\section{References}

1. Lloyd-Owen SJ, Donaldson GC, Ambrosino N, et al. Patterns of home mechanical ventilation use in Europe: results from the Eurovent survey. Eur Respir J 2005;25:1025-31.

2. Hind M, Polkey MI, Simonds AK. AJRCCM: 100-Year Anniversary. Homeward Bound: A Centenary of Home Mechanical Ventilation. Am J Respir Crit Care Med 2017;195:1140-9.

3. Melloni B, Mounier L, Laaban JP, et al. Home-Based Care Evolution in Chronic Respiratory Failure between 2001 and 2015 (Antadir Federation Observatory). Respiration 2018;96:446-54.

4. Hodgson LE, Murphy PB. Update on clinical trials in home mechanical ventilation. J Thorac Dis 2016;8:255-67.

5. Suh ES, Murphy PB, Hart N. Home mechanical ventilation for chronic obstructive pulmonary disease: What next after the HOT-HMV trial? Respirology 2019;24:732-9.

6. Park S, Suh ES. Home mechanical ventilation: back to basics. Acute Crit Care 2020;35:131-41.

7. Park M, Jang H, Sol IS, et al. Pediatric Home Mechanical Ventilation in Korea: the Present Situation and Future Strategy. J Korean Med Sci 2019;34:e268.

8. Kim HI, Cho JH, Park SY, et al. Home Mechanical Ventilation Use in South Korea Based on National Health Insurance Service Data. Respir Care 2019;64:528-35.

9. Valko L, Baglyas S, Gal J, et al. National survey: current prevalence and characteristics of home mechanical ventilation in Hungary. BMC Pulm Med 2018;18:190.

10. Garner DJ, Berlowitz DJ, Douglas J, et al. Home mechanical ventilation in Australia and New Zealand. Eur Respir J 2013;41:39-45.

11. Sobotka SA, Gaur DS, Goodman DM, et al. Pediatric patients with home mechanical ventilation: The health services landscape. Pediatr Pulmonol 2019;54:40-6.

12. Nonoyama ML, McKim DA, Road J, et al. Healthcare utilisation and costs of home mechanical ventilation. Thorax 2018. [Epub ahead of print]. doi: 10.1136/ thoraxjnl-2017-211138.

13. Chatwin M, Heather S, Hanak A, et al. Analysis of home support and ventilator malfunction in 1,211 ventilatordependent patients. Eur Respir J 2010;35:310-6.

14. King AC. Long-term home mechanical ventilation in the United States. Respir Care 2012;57:921-30; discussion 930-2.

15. Windisch $W$, Quality of life in home mechanical ventilation study group. Impact of home mechanical 
ventilation on health-related quality of life. Eur Respir J 2008;32:1328-36.

16. Lee YH, Han K, Ko SH, et al. Data Analytic Process of a Nationwide Population-Based Study Using National Health Information Database Established by National Health Insurance Service. Diabetes Metab J 2016;40:79-82.

17. Nasiłowski J, Wachulski $M$, Trznadel W, et al. The evolution of home mechanical ventilation in poland between 2000 and 2010. Respir Care 2015;60:577-85.

18. Kim DH, Kang SW, Choi WA. Home mechanical ventilation in South Korea. Yonsei Med J 2014;55:1729-35.

19. Chu CM, Yu WC, Tam CM, et al. Home mechanical ventilation in Hong Kong. Eur Respir J 2004;23:136-41.

20. Graham RJ, Fleegler EW, Robinson WM. Chronic ventilator need in the community: a 2005 pediatric census of Massachusetts. Pediatrics 2007;119:e1280-7.

21. Gowans M, Keenan HT, Bratton SL. The population prevalence of children receiving invasive home ventilation in Utah. Pediatr Pulmonol 2007;42:231-6.

22. McKim DA, Road J, Avendano M, et al. Home mechanical

Cite this article as: Song K, Kim SW, Sim YS, Park TS, Lee YS, Ha JH, Park JY, Jung KS, Park S. Cross-sectional survey on home mechanical ventilator use: major deficiencies in a home care system in South Korea. J Thorac Dis 2021;13(7):42714280. doi: $10.21037 /$ jtd-21-269 ventilation: a Canadian Thoracic Society clinical practice guideline. Can Respir J 2011;18:197-215.

23. Windisch W, Geiseler J, Simon K, et al. German National Guideline for Treating Chronic Respiratory Failure with Invasive and Non-Invasive Ventilation: Revised Edition 2017 - Part 1. Respiration 2018;96:66-97.

24. López-Bastida J, Perestelo-Pérez L, Montón-Alvarez F, et al. Social economic costs and health-related quality of life in patients with amyotrophic lateral sclerosis in Spain. Amyotroph Lateral Scler 2009;10:237-43.

25. Landfeldt E, Lindgren P, Bell CF, et al. The burden of Duchenne muscular dystrophy: an international, crosssectional study. Neurology 2014;83:529-36.

26. Liu JF, Lu MC, Fang TP, et al. Burden on caregivers of ventilator-dependent patients: A cross-sectional study. Medicine (Baltimore) 2017;96:e7396.

27. Yang L, Nonoyama M, Pizzuti R, et al. Home mechanical ventilation: A retrospective review of safety incidents using the World Health Organization International Patient Safety Event classification. Can J Respir Ther 2016;52:85-91. 


\section{Case Report Form 1}

Survey on home mechanical ventilator use in South Korea

Patient Number:

Age:_yrs Gender: $\mathrm{M} \square / \mathrm{F} \square$ Body weight:_ kg Height:_ cm

Area (province/coity):L

Housing type: Single house $\square$ Condominium $\square$ Apertment $\square$ Others

Number of family living toger: (including the subject on HMV)

1.Which underlying comorbidities do you have? (multiple select)

DM $\square$, Hypertension $\square$, COPD $\square$, Heart disease $\square$, Chronic kidney
disease $\square$,
Cerebral infarct or bleeding $\square$, Chronic hepatitis $\square$, Cancer $\square$,
Others $\square$

2. When did you start the HMV?/ (month/year) (total duration months)

3.Where are you using a HMV now? Home $\square$, Hursing home $\square$, Hospital $\square$, (Other)

4. Tracheostomy ventilation? $\quad$ Yes $\square$, No

If no, which type of mask do you use? $\quad$ Nasal mask $\square$, Facial mask $\square$, Others:

5. Feeding methods (one of the two)

$\square$ Tube feeding (if yes, L-tube $\square$ vs. PEG $\square$ )

$\square$ Oral feeding

6. How frequent do you change the machines or devices per year?

6-1) Ventilator machine: $\frac{\mathrm{yr}}{6-2)}$

6-2) Masks: /yr(only for mask users)

6-3) Circuits: /yr

7. Which ancillary devices do you have now? (multiple select)

Oxygen monitoring $\square, \mathrm{CO}_{2}$ monitoring $\square$, Cough assist

Chest wall oscillation $\square$, Suctioning device $\square$, AMBU-bag $\square$, Oxygen

generator $\square$

8. Who cares for the subject and ventilators?

Family member $\square$, Privately hired caregiver $\square$, Self $\square$, Others:

9. Regular home visit services (frequency)

9-1) By a specialized nurse: /month

9-2) By a HMV provider: /month

10. Any emergencies at home during the last year?

10-1) Frequency: /yr

10-2) Please explain in detail: 1 )

2) 
11. Any visits to hospitals for problems associated with HMV or patient's condition during the last year? 11-1) Visit to outpatient office $\quad$ Yes $\square$ No $\square$

11-2) Visit to emergency department: Yes $\square$ No

12. Any hospitalizations for problems associated with HMV or patient's condition?

12-1) Hospitalization: $\quad$ Yes $\square$ No

12-2) Admission to the ICUs: Yes $\square$ No $\square$

13. National Health Insurance Service (Check only one)

National Health Insurance $\square$, Medical aid $\square$, Others:

14. How much do you pay per month (for out-of-pocket expenses associated with patient's care) Korean won/month

15. Any comments?

$\rightarrow$

Thank you for answering this questionnaire. 


\section{Case Report Form 2}

Survey on home mechanical ventilator use in South Korea

(Parameters associated with ventilator machines)

Patient Number:

1. Primary diagnosis (indication) for the use of home mechanical ventilation (HMV).

1-1) Diagnosis:

1-2) ICD-10 code 1) 2) 3)

2. What is the brand name of the home ventilator?

(this is to distinguish between life-support and non-life-support ventilators)

3. Daily hours on HMV

$\square$ 24-h use (full-day use)

$\square$ Part-time use (hours/day)

4. Type of interfaces (masks)

Facial mask $\square$ Nasal mask $\square$ Nasal pillow $\square$ 기타 :

5. Type of circuits

$\square$ Single-limb circuit with a leak valve (an exhalation port)

$\square$ Single-limb circuit with an exhalation valve

$\square$ Double-limb circuit

6. Ventilator settings.

\begin{tabular}{|l|c|c|c|c|c|c|}
\hline Mode & Oxygen supplied & IPAP & EPAP & Tidal volume & 호흡수 (set RR) & I:E ratio \\
\hline & $(1 / \mathrm{min})$ & & & $\mathrm{ml}$ & \multicolumn{2}{|l}{} \\
\hline Leak & & & & & & \\
\hline L/min & & & & & & \\
\hline
\end{tabular}

Thank you for answering this questionnaire. 
Table S1 Primary diagnosis for HMV use

\begin{tabular}{|c|c|c|}
\hline Primary diagnosis & Adults ( $n=38), n(\%)$ & Children $(n=26), n(\%)$ \\
\hline Pulmonary arterial hypertension & $1(2.6)$ & $1(3.8)$ \\
\hline Kyphoscoliosis & $3(7.9)$ & $1(3.8)$ \\
\hline Central sleep apnea & $2(5.3)$ & $0(0.0)$ \\
\hline Cerebrovascular accident & $2(5.3)$ & $0(0.0)$ \\
\hline Hypoxic brain damage & $0(0.0)$ & $1(3.8)$ \\
\hline \multicolumn{3}{|l|}{ Neuromuscular disorders } \\
\hline Amyotrophic lateral sclerosis & $3(7.9)$ & $0(0.0)$ \\
\hline \multicolumn{3}{|l|}{ Genetic disorders } \\
\hline Mucopolysaccharidosis type I & $0(0.0)$ & $1(3.8)$ \\
\hline Gaucher's disease & $0(0.0)$ & $1(3.8)$ \\
\hline Pompe disease & $1(2.6)$ & $0(0.0)$ \\
\hline Rett syndrome & $1(2.6)$ & $0(0.0)$ \\
\hline \multicolumn{3}{|l|}{ Congenital respiratory disorders } \\
\hline Bronchopulmonary dysplasia & $0(0.0)$ & $3(11.5)$ \\
\hline Malformations of trachea and bronchus & $0(0.0)$ & $2(7.7)$ \\
\hline
\end{tabular}

HMV, home mechanical ventilation. 
Table S2 Emergences incidents associated with HMV use at home ${ }^{\dagger}$

\begin{tabular}{lc}
\hline Incidents & Numbers \\
\hline Dyspnea (tachypnea) & 17 \\
Pneumonia & 8 \\
Tracheostomy obstruction & 3 \\
Tracheostomy dislocation & 1 \\
PEG malfunction & 3 \\
Hypoxemia & 2 \\
Copious secretion & 1 \\
Arrhythmia & 1 \\
High fever & 1 \\
Syncope & 1 \\
Seizure & 1 \\
Ventilator alarm & 2 \\
\hline
\end{tabular}

${ }^{\dagger}$, a total of 42 incidents occurred in 28 patients during the last 1 year. HMV, home mechanical ventilation; PEG, percutaneous endoscopic gastrostomy.

Table S3 Data on 9 subjects who died while receiving HMV

\begin{tabular}{|c|c|c|c|c|c|}
\hline No & Age (years) & Primary diagnosis for HMV & Duration of $\mathrm{HMV}$ (months) ${ }^{\dagger}$ & Interface & Cause of death \\
\hline 2 & 77 & COPD & 52.0 & Facial mask & Disease progression \\
\hline 3 & 81 & COPD & 9.0 & Tracheostomy & Disease progression \\
\hline 4 & 49 & Unspecified respiratory disorder & 17.0 & Facial mask & Disease progression \\
\hline 6 & 66 & NMD & 19.0 & Tracheostomy & Disease progression \\
\hline 7 & 68 & CSA & 24.0 & Tracheostomy & Disease progression \\
\hline 8 & 17 & Unspecified respiratory disorder & 7.0 & Tracheostomy & Unexpected \\
\hline 9 & 7 & Unspecified encephalopathy & 32.0 & Tracheostomy & Unexpected \\
\hline
\end{tabular}

${ }^{\dagger}$, at the time of death. COPD, chronic obstructive pulmonary disease; CSA, central sleep apnea; HMV, home mechanical ventilation; NMD, neuromuscular disorder. 